\title{
Malaria parasitemia and its association with lipid and hematological parameters among malaria- infected patients attending at Metema Hospital, Northwest Ethiopia
}

\author{
This article was published in the following Dove Press journal: \\ Pathology and Laboratory Medicine International \\ 18 October 2016 \\ Number of times this article has been viewed
}

\section{Solomon Sirak $1, *$ \\ Abebe Alemu Fola ${ }^{2}$ \\ Ligabaw Worku ${ }^{3}$ \\ Belete Biadgo ${ }^{4, *}$ \\ 'Department of Medical Laboratory Sciences, College of Medicine and Health Sciences, Debre Tabor University, Debre Tabor, Ethiopia; ${ }^{2}$ Walter and Eliza Hall Institute of Medical Research, Melbourne, VIC, Australia; ${ }^{3}$ Department of Medical Parasitology, School of Biomedical and Laboratory Sciences, College of Medicine and Health Sciences, University of Gondar, Gondar, Ethiopia; ${ }^{4}$ Department of Clinical Chemistry, School of Biomedical and Laboratory Sciences, College of Medicine and Health Sciences, University of Gondar, Gondar, Ethiopia}

*These authors contributed equally to this work

Correspondence: Belete Biadgo

Department of Clinical Chemistry, School of Biomedical and Laboratory

Sciences, College of Medicine and Health Sciences, University of Gondar, PO Box

196, Gondar, Ethiopia

Tel +25 | 9| 829507 |

Email beletebiadigo@yahoo.com
Background: Malaria is a major public health problem in Ethiopia with wide-ranging hematological and biochemical alterations. Therefore, the aim of this study was to assess malaria parasitemia and its association with lipid and hematological parameters.

Methods: A comparative cross-sectional study was conducted from April 1 to June 30, 2014. Of 200 study participants, 100 were confirmed malaria patients and 100 healthy controls. Study participants were included based on systematic random sampling techniques. Seven milliliters of blood samples were collected for investigation of hematological and lipid parameters. Data were entered and analyzed using SPSS-20 statistical software. Independent $t$-test and one-way analysis of variance were run to compare mean differences. A $P<0.05$ was considered as statistically significant.

Results: A total of 200 study participants $(78.5 \%$ males and $21.5 \%$ females $)$ were included with a mean age of $24.67 \pm 11.2$ years. A majority of malaria patients were infected with Plasmodium falciparum (66\%). According to parasitic load, 38\%, 52\%, and 10\% patients were reported with low, moderate, and high malaria parasitemia, respectively. There were statistically significant mean differences in white blood cells count $\left([6.875 \pm 3.20\right.$ vs $\left.5.835 \pm 2.01] \times 10^{3} / \mu \mathrm{L}\right)$, neutrophil $(63.1 \% \pm 8.7 \%$ vs $56.0 \% \pm 12.7 \%)$, hemoglobin ( $11.9 \pm 2.0$ vs $14.5 \pm 3.0 \mathrm{gm} / \mathrm{dL})$, hematocrit $(36.2 \% \pm 7.8 \%$ vs $42.4 \% \pm 8.3 \%)$, platelet count $\left([175.3 \pm 136\right.$ vs $\left.193.4 \pm 81.9] \times 10^{3} / \mu \mathrm{L}\right)$, high-density lipoprotein (19.6 \pm 13.7 vs $35.5 \pm 12.3 \mathrm{mg} / \mathrm{dL})$, low-density lipoprotein $(34.7 \pm 23.5$ vs $64.5 \pm 29.3 \mathrm{mg} / \mathrm{dL})$, triglyceride $(118.0 \pm 61.3 \mathrm{vs} 101.7 \pm 36.8 \mathrm{mg} / \mathrm{dL})$, and total cholesterol $(88.0 \pm 36.3$ vs $148.7 \pm 39.1 \mathrm{mg} / \mathrm{dL})$ for cases and controls, respectively $(P<0.05)$. In patients with different densities of malaria parasitemia there were statistically significant differences in total red blood cells count ([4.4 \pm 0.8 vs $4.8 \pm 0.8$ vs $5.3 \pm 0.7] \times 106 / \mu \mathrm{L})$, hemoglobin concentration ([11.9 \pm 1.8 vs $11.6 \pm 1.8$ vs $13.4 \pm 3.0] \mathrm{gm} / \mathrm{dl})$, and platelet count ([227.1 \pm 131 vs $186.8 \pm 175 \mathrm{vs}$ $156.9 \pm 100] \times 103 / \mathrm{uL}$ ) among low, moderate, and high parasitemia, respectively.

Conclusion: This study revealed that routinely used laboratory tests such as lipid and hematological parameters could be good and reliable adjunct in the early diagnosis of malaria-infected patients with mild-to-severe parasitemia in malaria endemic areas.

Keywords: malaria parasitemia, hematological parameters, lipid parameters, Ethiopia

\section{Introduction}

Malaria is a disease in humans caused by parasitic protozoan of the genus Plasmodium and it is a severe public health problem in most countries of the tropics and sub tropics. ${ }^{1}$ According to World Health Organization 2012 estimation, there were about 
209 million cases of malaria in the world, and Sub-Saharan Africa was the most affected region with estimated deaths of 627,000 being reported. ${ }^{2}$ Based on Ethiopia's Federal Ministry of Health in 2009/2010, malaria infection was the leading cause of outpatient visit admissions, accounting for $14 \%$ and nearly $9 \%$ of admissions, and it was among the ten leading causes of inpatient deaths in children and pregnant mothers. ${ }^{3}$

Malaria parasites utilize cholesterol and phospholipids for survival in their human host. ${ }^{4}$ For these parasites, circulating high-density lipoprotein (HDL) particles and erythrocytic membrane are the potential sources of cholesterol, whereas the source of phospholipids is erythrocytic membrane. ${ }^{5}$ Most plasma apolipoproteins, endogenous lipids, and lipoproteins have their origin in the liver, which depends on cellular integrity and functionality of the hepatocytes. ${ }^{6}$ The major lipid component lipoproteins in plasma are chylomicrons, very low-density lipoproteins (VLDL), low-density lipoprotein (LDL), HDL, and free fatty acids. A population-based study on common lipid parameters showed that cholesterol value are lower in Africa, where malaria is endemic, than in many other parts of the world. Hypolipoproteinemia, with lower levels of lipids such as total cholesterol (TC), HDL, and LDL, was observed in patients suffering from malaria caused by P. falciparum species. ${ }^{7}$

Hematological alterations are some of the most common complications that cause changes in major cell lines such as red blood cells (RBCs), white blood cells (WBCs), and platelets. ${ }^{8}$ With regard to the association between blood cells and malaria infection, analysis of hematological parameters indicates increased predictive value. ${ }^{9}$ In spite of causing complication and malaria pathology, hematological changes such as anemia, thrombocytopenia, and leukocytosis or leukopoenia have been reported but the degree of alterations varies according to the level of malaria endemicity, nutritional status, background hemoglobinopathy, socio-demographic factors, and malaria immunity. ${ }^{10}$ The extent of serum lipid and hematological parameters changes during malarial infection and their underlying biological mechanisms in level of parasitemia remain unclear. Because of this, knowing about malaria and its association with lipid and hematological parameters could be important for management of malariainfected patients and better understanding in this relationship is crucial in the development of potential drug. Therefore, the aim of this study was to assess malaria parasitemia and its association with lipid and hematological parameters among malaria-infected patients attending at Metema Hospital, Northwest Ethiopia.

\section{Materials and methods}

A comparative cross-sectional study was conducted from April 1 to June 30, 2014 at Metema Hospital, Gendewuha town in Northwest Ethiopia. Metema district is located at $36^{\circ} 17^{\prime} \mathrm{E}$ and $12^{\circ} 39 \mathrm{~N}$ ' in North Gondar about $900 \mathrm{~km}$ northwest of Addis Ababa and about $180 \mathrm{~km}$ west of Gondar town. The district has an international boundary of $>60 \mathrm{~km}$ long between Ethiopia and Sudan. The altitude of Metema ranges from as low as 550 to $1,608 \mathrm{~m}$ above sea level, while the minimum annual temperature ranges between $22^{\circ} \mathrm{C}$ and $28^{\circ} \mathrm{C}$. Daily temperatures are very high during the months from March to May, where it may increase to as high as $43^{\circ} \mathrm{C}$. Mean annual rainfall for the area ranges from $\sim 850$ to $1,100 \mathrm{~mm}$. It has a unimodal rainfall pattern. The rainy months extend from June until the end of September. However, most of the rainfall is received during the months of July and August. This area is malarious and has only one district hospital that serves the 110,000 people who live in Metema and neighboring districts. ${ }^{11,12}$

\section{Study population}

The study population consisted of malaria patients who had clinical signs and symptoms of malarial infection. The results were investigated by experienced medical laboratory scientist for confirmation of malaria infection. Patients who had been infected only with malaria were included after confirmed laboratory test for malarial infection. Patients who had any viral, parasitic, and bacterial infection after laboratory investigation in addition to malaria were excluded from the study. As control, age- and sex-matched apparently healthy participants were examined in parallel using the same investigative techniques.

\section{Sample size and sampling techniques}

Sample size calculation was done based on two population means formula using Open Epi Version 2.3 open source calculator software (Emory University, Rollins School of Public Health, USA) and the mean and standard deviation of VLDL were taken from a previous study. ${ }^{13}$ Two-sided confidence intervals, $80 \%$ power, and desired ratio of sample size of cases to controls were 1, giving a total sample size of 200. Systematic random sampling techniques were employed to recruit the study participants.

\section{Data collection and laboratory methods}

Socio-demographic and clinical data were collected using a pretested semi-structured questionnaire by trained clinical nurses. Seven milliliters of venous blood samples were collected by sterile venipuncture procedures; $4 \mathrm{~mL}$ in a plain test 
tube was used for lipid profile investigation, $3 \mathrm{~mL}$ in ethylenediaminetetraacetic acid anticoagulant tubes (K3 EDTA; BD Vacutainer System, Beliver Industrial Estate, UK) was used for hematological parameters; the samples were analyzed using the electronic cell counter, BC-5200 Mindray (Mindray, Nanshan, Shenzhen, People's Republic of China) hematology analyzer. Two drops of blood for making thick and thin blood smear film were taken and examined by a senior medical laboratory scientist. Lipid profiles were determined using a commercial kit by Biosystem A25 (Biosystem, Barcelona, Spain) clinical chemistry analyzer. LDL concentrations were determined by Friedewald equation. VLDL concentrations were estimated using the assumption that in fasting subjects, the VLDL cholesterol to total plasma triglyceride (TG) ratio is relatively fixed at 1:5. Daily internal quality controls and the scheduled external quality assessment program were done according to the manufacturer's instruction.

\section{Detection and quantification of malaria parasites}

Two drops of capillary blood sample were added on a microscope slide to prepare a thin and thick smear for the detection of malaria parasite density and malaria species. Standard operational procedures were prepared for identification of malaria species and for the detection of malaria parasitemia. Estimations of malaria parasites based on thick and thin smear for parasite density against $200 \mathrm{WBCs}$ were done and expressed as the number of parasites per microliter of blood, assuming an average WBC count of 8,000 cells/ $\mu \mathrm{L}$ of blood multiplied by 100 . Number of malaria parasites per microliter of blood $=$ number of parasites $\times(8,000 /$ number of WBCs counted $) .{ }^{14}$

\section{Data management and quality control}

The questionnaire was pretested for its accuracy and consistency prior to actual data collection and one-day training was given to the data collectors. Furthermore, the principal investigator provided feedback and corrections on a daily basis to the data collectors. Completion, accuracy, and clarity of the collected data were checked carefully on a regular basis. The results obtained from quality control samples must be within mean \pm 2 standard deviation of the given Levey-Jennings chart for lipid profiles. For malaria parasite identification and load calculations, we used known positive and negative control thick and thin blood smears. Randomly $10 \%$ of the total slides were selected and re-examined at the end by experienced Medical laboratory Scientist who were blinded for the first examination result. Therefore, to ensure the quality of the final results, pre-analytical, analytical, and post-analytical precautions were taken.

\section{Data analysis and interpretation}

Data were entered and analyzed using SPSS software version 20. Descriptive statistics were done. An independent $t$-test was used to show mean differences of lipid and hematological profiles among malaria patients and control groups. Analysis of variance was employed to know mean differences of lipid and hematological profiles among low, moderate, and high malaria parasitemia grades. $P$-values $<0.05$ were considered as statistically significant.

\section{Ethical consideration}

Ethical clearance related to research involving human subjects were obtained from the Institutional Review Board of University of Gondar. Before the actual data collection, permission was obtained from the medical director of Metema Hospital, assent and informed written consent was obtained from the patients. In addition, confidentiality of the study subjects was maintained. Patient information was anonymized and a code was used instead of personal identifier prior to this analysis. Finally, the result was communicated to clinicians to treat patients according to World Health Organization treatment guideline for malaria patients. ${ }^{15}$

\section{Results}

Data for this study were obtained from 200 malaria-infected patients and healthy controls recruited for the study, with all parameters available. The mean age of the study participants was $24.67 \pm 11.2$ years. A majority of the study participants were males with $78 \%$ and $79 \%$ for cases and controls, respectively. The predominant age group was $16-30$ years. The majority of the study participants were from rural residence, $56 \%$ and $59 \%$ for cases and controls, respectively (Table 1).

This study indicated that a higher proportion of malaria patients were infected with $P$. falciparum (66\%), and the predominant age group affected by malaria parasite was 16-30 years (70\%). According to the degree of parasitemia, majority had moderate parasitemia (Table 2).

The study showed statistically significant differences in lipid and hematological parameters between malariainfected and controls study participants. Hematocrit (Hct), hemoglobin $(\mathrm{Hgb})$, platelet, mean corpuscular hemoglobin concentration (MCHC), HDL, LDL, and TC were found to be significantly decreased in malaria-infected patients $(P<0.05)$. On the other hand, TG, WBC, and neutrophil counts were found to be significantly increased in malaria-infected patients compared to healthy controls. However, there were relative decreases in lymphocyte and total RBC counts in malaria-infected individuals, and the decreases were not statistically significant ( $P>0.05$; Table 3$)$. 
Table I Socio-demographic characteristics of the study participants at Metema Hospital, Northwest Ethiopia, 2014

\begin{tabular}{llll}
\hline Variables & $\begin{array}{l}\text { Malaria } \\
\text { patients (\%) }\end{array}$ & $\begin{array}{l}\text { Healthy } \\
\text { controls (\%) }\end{array}$ & Total (\%) \\
\hline Sex & & & \\
Male & $78(78)$ & $79(79)$ & $157(78.5)$ \\
Female & $22(22)$ & $21(21)$ & $43(21.5)$ \\
$\quad$ Total & $100(100)$ & $100(100)$ & $200(100)$ \\
Age (years) & & & \\
$\leq 15$ & $13(13)$ & $13(13)$ & $26(13)$ \\
I6-30 & $70(70)$ & $70(70)$ & $140(70)$ \\
$31-45$ & $11(11)$ & $11(11)$ & $22(11)$ \\
$\geq 46$ & $6(6)$ & $6(6)$ & $12(6)$ \\
$\quad$ Total & $100(100)$ & $100(100)$ & $200(100)$ \\
Occupation & & & $139(69.5)$ \\
Farmer & $76(76)$ & $63(63)$ & $27(13.5)$ \\
Merchant & $14(14)$ & $13(13)$ & $18(9)$ \\
Government & $8(8)$ & $10(10)$ & $16(8)$ \\
worker & & $14(14)$ & $200(100)$ \\
Daily laborer & $2(2)$ & $100(100)$ & $74(37)$ \\
Total & $100(100)$ & & $126(63)$ \\
Residence & & $41(41)$ & $200(100)$ \\
Urban & $33(44)$ & $59(59)$ & $100(100)$ \\
Rural & $67(56)$ & & \\
Total & $100(100)$ & & \\
\hline
\end{tabular}

Table 2 Prevalence of malaria parasite species and degree of parasitemia among malaria-infected patients $(\mathrm{N}=100)$ at Metema Hospital, Northwest Ethiopia, 2014

Variables Plasmodium Plasmodium Low (\%) Moderate High falciparum vivax (\%) $\quad$ (\%) $\quad(\%)$ (\%)

\begin{tabular}{llllll}
\hline $\begin{array}{l}\text { Sex } \\
\text { Male }\end{array}$ & $54(81.8)$ & $24(70.6)$ & $30(79.0)$ & $40(76.9)$ & $8(80.0)$ \\
$\begin{array}{l}\text { Female } \\
\text { Age (years) }\end{array}$ & $12(18.2)$ & $10(29.4)$ & $8(21.0)$ & $12(23.1)$ & $2(20.0)$ \\
$\leq 15$ & $10(15.2)$ & $3(8.8)$ & $3(7.9)$ & $8(15.4)$ & $2(20.0)$ \\
$16-30$ & $44(66.7)$ & $26(76.5)$ & $28(73.7)$ & $36(69.2)$ & $6(60.0)$ \\
$31-45$ & $7(10.6)$ & $4(11.8)$ & $4(10.5)$ & $5(9.6)$ & $2(20.0)$ \\
$\geq 46$ & $5(7.6)$ & $1(2.9)$ & $3(7.9)$ & $3(5.8)$ & $0(0)$ \\
Total & $66(66.0)$ & $34(34.0)$ & $38(38.0)$ & $52(52.0)$ & $10(10.0)$ \\
\hline
\end{tabular}

Malaria-infected individuals were grouped according to their density of parasitemia. There was a statistically significant association among malaria densities and the level of total RBC, platelet counts, and Hct concentration, but such an association was not observed $(P>0.05)$ between parasite density versus other hematological and lipid parameters (Table 4).

\section{Discussion}

Malaria causes a major public health problem in people living in the highly affected areas of North Gondar. Evidences suggested that lipid and hematological parameters are altered in malaria-infected patients. Changes in hematological
Table 3 Lipid and hematological parameters among malariainfected patients and control groups, at Metema Hospital, Northwest Ethiopia, 2014

\begin{tabular}{|c|c|c|c|}
\hline Parameters & $\begin{array}{l}\text { Malaria patients } \\
\text { (mean } \pm \text { SD) }\end{array}$ & $\begin{array}{l}\text { Control groups } \\
\text { (mean } \pm \text { SD) }\end{array}$ & $P$-value \\
\hline WBCs $\left(\times 10^{3} / \mu \mathrm{L}\right)$ & $6.875 \pm 3.20$ & $5.835 \pm 2.01$ & $0.006 *$ \\
\hline Lymphocyte (\%) & $29.7 \pm 10.4$ & $31.09 \pm 11.60$ & 0.374 \\
\hline $\begin{array}{l}\text { Mixed cell } \\
\text { population (\%) }\end{array}$ & $13.2 \pm 6.7$ & $12.8 \pm 5.4$ & 0.671 \\
\hline Neutrophil (\%) & $63.1 \pm 8.7$ & $56.0 \pm 12.7$ & $0.000 *$ \\
\hline RBCs $\left(\times 10^{6} / \mu \mathrm{L}\right)$ & $4.729 \pm 0.8$ & $4.862 \pm 0.9$ & 0.290 \\
\hline $\mathrm{Hgb}(\mathrm{gm} / \mathrm{dL})$ & $11.9 \pm 2.0$ & $14.5 \pm 3.0$ & $0.000 *$ \\
\hline Hct (\%) & $36.2 \pm 7.8$ & $42.4 \pm 8.3$ & $0.000 *$ \\
\hline Platelet $\left(\times 10^{3} / \mu \mathrm{L}\right)$ & $175.3 \pm 136.0$ & $193.4 \pm 81.9$ & $0.000 *$ \\
\hline MCV (fl) & $74.06 \pm 12.6$ & $70.34 \pm 15.0$ & 0.059 \\
\hline $\mathrm{MCH}(\mathrm{pg})$ & $29.8 \pm 2.9$ & $30.8 \pm 5.4$ & 0.085 \\
\hline $\mathrm{MCHC}(\mathrm{gm} / \mathrm{dL})$ & $29.3 \pm 17.1$ & $41.5 \pm 6.7$ & $0.000 *$ \\
\hline HDL-c (mg/dL) & $19.6 \pm 13.7$ & $35.5 \pm 12.3$ & $0.000 *$ \\
\hline LDL-c (mg/dL) & $34.7 \pm 23.5$ & $64.5 \pm 29.3$ & $0.000 *$ \\
\hline VLDL-c (mg/dL) & $23.8 \pm 12.4$ & $22.0 \pm 8.2$ & 0.224 \\
\hline Triglyceride (mg/dL) & $118.0 \pm 61.3$ & $101.7 \pm 36.8$ & $0.023 *$ \\
\hline $\begin{array}{l}\text { Total cholesterol } \\
(\mathrm{mg} / \mathrm{dL})\end{array}$ & $88.0 \pm 36.3$ & $148.7 \pm 39.1$ & $0.000 *$ \\
\hline
\end{tabular}

Note: $* P<0.05$ is statistically significant.

Abbreviations: Hct, hematocrit; HDL-c, high-density lipoprotein cholesterol; Hgb, hemoglobin; LDL-c, low-density lipoprotein cholesterol; $\mathrm{MCH}$, mean corpuscular hemoglobin; MCHC, mean corpuscular hemoglobin concentration; MCV, mean cell volume; mixed cell population, basophil, eosinophil, and monocyte together in the analyzer reading; RBCs, red blood cells; SD, standard deviation; VLDL, very lowdensity lipoproteins; WBCs, white blood cells.

parameters among malaria-infected patients have been reported. ${ }^{16}$ A previous study has reported pancytopenia as a hematological abnormality caused by malarial infection. ${ }^{17}$

This study showed statistically significant differences in $\mathrm{WBC}$ and neutrophil count, Hgb, Hct, MCHC, platelets, TC, HDL, TG, and LDL concentrations between malariainfected patients and controls. In terms of WBC indices, there were statistically significant differences in the counts of total WBCs and neutrophils and non-significant decreases in lymphocytes and mixed cell population in case of malariainfected patients compared to the controls $(P>0.05)$. In agreement, a study in Nigeria showed significantly higher level of total WBCs in malaria-infected patients than controls and the higher number of WBCs and neutrophils were found to be a major feature in malaria-infected patients. ${ }^{18}$ This is due to an increase in the release of WBCs at the initial stage of infection to fight against malaria infection. This study supports previous studies that report effective immune response to malaria is a feature in malaria endemic areas. ${ }^{18,19}$

In contrast, a study conducted in India reported that malaria parasitemia tended to significantly lower WBC counts in patients compared to controls. ${ }^{20}$ Although, some 
Table 4 Lipid and hematological parameters in different densities of malaria parasitemia among malaria patients $(\mathrm{N}=100)$ at Metema Hospital, Northwest Ethiopia, 2014

\begin{tabular}{|c|c|c|c|c|}
\hline $\begin{array}{l}\text { Parameter } \\
(\mathrm{mg} / \mathrm{dL})\end{array}$ & $\begin{array}{l}\text { Low } \\
(n=32)\end{array}$ & $\begin{array}{l}\text { Moderate } \\
(n=52)\end{array}$ & $\begin{array}{l}\text { High } \\
(n=10)\end{array}$ & $P$-value \\
\hline \multicolumn{5}{|l|}{ Lipid parameters } \\
\hline HDL (mg/dL) & $22.4 \pm 14.5$ & $19.9 \pm 12.6$ & $18.9 \pm 14.5$ & 0.758 \\
\hline LDL (mg/dL) & $30.7 \pm 9.7$ & $24.5 \pm 3.9$ & $21.2 \pm 2.9$ & 0.406 \\
\hline VLDL (mg/dL) & $24.3 \pm 8.1$ & $24.3 \pm 14.4$ & $24.3 \pm \mid 4.1$ & 0.894 \\
\hline $\begin{array}{l}\text { Triglyceride } \\
(\mathrm{mg} / \mathrm{dL})\end{array}$ & $|I 5 \pm 5| .4$ & $|20 \pm 7| .2$ & $119 \pm 42$ & 0.939 \\
\hline $\begin{array}{l}\text { Total cholesterol } \\
(\mathrm{mg} / \mathrm{dL})\end{array}$ & $107.6 \pm 43.4$ & $93.4 \pm 41.6$ & $81.1 \pm 28.9$ & 0.068 \\
\hline \multicolumn{5}{|l|}{ WBC indices } \\
\hline TWBC $\left(\times 10^{3} / \mu \mathrm{L}\right)$ & $6.25 \pm 2.4$ & $7.28 \pm 3.4$ & $7.12 \pm 4.4$ & 0.310 \\
\hline Lymphocyte (\%) & $28.4 \pm 10.5$ & $29.8 \pm 10.4$ & $34.3 \pm 9.4$ & 0.282 \\
\hline $\begin{array}{l}\text { Mixed cell } \\
\text { population (\%) }\end{array}$ & $13.2 \pm 3.0$ & $13.4 \pm 8.7$ & $12.3 \pm 3.2$ & 0.887 \\
\hline Neutrophil (\%) & $61.8 \pm 8.9$ & $60.4 \pm 11.1$ & $64.6 \pm 8.0$ & 0.203 \\
\hline $\mathrm{RBC}$ indices & & & & \\
\hline $\begin{array}{l}\text { Total RBC } \\
\left(\times 10^{6} / \mu \mathrm{L}\right)\end{array}$ & $5.3 \pm 0.7$ & $4.8 \pm 0.8$ & $4.4 \pm 0.8$ & $0.007^{*}$ \\
\hline $\mathrm{Hgb}(\mathrm{gm} / \mathrm{dL})$ & $13.4 \pm 3.0$ & $11.6 \pm 1.8$ & $11.9 \pm 1.8$ & $0.013^{*}$ \\
\hline $\mathrm{Hct}(\%)$ & $40.1 \pm 8.5$ & $36.7 \pm 7.0$ & $34.5 \pm 8.2$ & 0.103 \\
\hline $\mathrm{MCV}(\mathrm{fl})$ & $72.6 \pm 14.5$ & $76.2 \pm 10.6$ & $74.1 \pm 7.2$ & 0.311 \\
\hline $\mathrm{MCH}$ (pg) & $30.4 \pm 2.7$ & $29.4 \pm 3.0$ & $29.8 \pm 2.5$ & 0.216 \\
\hline $\mathrm{MCHC}(\mathrm{gm} / \mathrm{dL})$ & $32.9 \pm 170$ & $31.9 \pm 152$ & $26.2 \pm 188$ & 0.188 \\
\hline Platelet $\left(\times 10^{3} / \mu \mathrm{L}\right)$ & $227.1 \pm 131$ & $186.8 \pm 175$ & $156.9 \pm 100$ & $0.027^{*}$ \\
\hline
\end{tabular}

Notes: $* P<0.05$ is statistically significant. Data presented as mean \pm standard deviation. Abbreviations: Hct, hematocrit; HDL, high-density lipoprotein; Hgb, hemoglobin; $\mathrm{LDL}$, low-density lipoprotein; $\mathrm{MCH}$, mean corpuscular hemoglobin; $\mathrm{MCHC}$ mean corpuscular hemoglobin concentration; MCV, mean cell volume; mixed cell population, basophil, eosinophil, and monocyte together in the analyzer reading; RBC, red blood cell; TWBC, total white blood cells; VLDL, very low-density lipoproteins; WBC, white blood cell.

discrepancies appear to exist, there have been reports of leukopenia as well as leukocytosis in malarial infection ${ }^{21}$ and studies have reported that neutropenia, eosinophilia, neutrophilia, and monocytosis are other hematological reactions to malarial infection..$^{22}$ This finding is found to be in contrast to previous studies which reported that malaria-induced changes include a reduction in neutrophil counts. ${ }^{18,23}$ In their report, reduction in neutrophil was observed as an important abnormality in patients with severe malaria and associated with a poor prognosis. The reason for this variation might be the marginalization of neutrophils to the sites of inflammation, splenic localization, and serum lymphotoxic factors.

With respect to $\mathrm{RBC}$ indices, total $\mathrm{RBC}$ and $\mathrm{MCH}$ counts non-significantly decreased but $\mathrm{Hgb}$, Hct, and $\mathrm{MCHC}$ showed statistically significant decrement in malaria patients compared to controls. This is in agreement with previous studies. ${ }^{20,24,25}$ These lower values might be due to the variety of morphological changes exhibited by RBCs, malaria-associated changes in composition of plasma, mechanical destruction of infected RBCs, and intravascular hemolysis caused by non-immune destruction of infected RBCs in case of high parasitemia. The other hypothesis might be changes in the RBC antigen structure caused by the parasitic invasion that stimulate the production of antibodies to RBCs, which triggers immune-mediated RBC lysis. Similar results were also presented in a previous study ${ }^{26}$ that demonstrated a decrease in Hct levels in febrile illness patients, indicating that reduction in most RBCs indices might be involved.

In addition, the values of mean corpuscular volume in malaria-infected patients were increased. However, the increment was not statistically significant. This might be due to anemia associated with malaria that causes increased rate of $\mathrm{RBC}$ production leading to the release of immature RBCs into blood circulation. This study suggested that due to abnormalities in the nitric oxide (NO) levels that occur in malarial infection, the mean corpuscular volume might be increased. In addition, $\mathrm{NO}$ can inhibit the enzyme methionine synthase, so functional vitamin $\mathrm{B}_{12}$ deficiency state may occur, which can lead to megaloblastic anemia, and studies suggested that $\mathrm{NO}$ is associated with the low serum level of vitamin $\mathrm{B}_{12}{ }^{27,28}$

In this study, there were statistically significant differences in the number of platelets among malaria-infected patients compared to controls. Evidences supported that thrombocytopenia was observed in a majority of patients with malaria; it was also observed that at high parasitemia, the platelets were found to be significantly lower. It has been noted by a previous study that increasing levels of $P$. falciparum parasite density result in a decreased platelet count. ${ }^{29}$ This significant reduction might be due to hyper-reactive splenomegaly, splenic pooling, immunologically mediated reduction in platelet count, and increased consumption of the platelets in the periphery. However, bleeding due to cytopenia is very rare in malaria. ${ }^{18,20,23,30}$ Both mature parasitized RBCs and cytokines can activate the coagulation cascade; consumption of anti-thrombin III, increased concentration of fibrin degradation products, and increased splenic clearance of platelets contribute well to the coagulopathy and thrombocytopenia in malaria. ${ }^{31}$

A study revealed that the association between malaria infection and platelets count was also observed in animal models. ${ }^{32}$ The pathogenic mechanisms by which platelets mediate disease severity in patients with P. falciparum malaria remain to be elucidated. However, clinical studies have shown that platelets in patients infected with P. falciparum expressed toll-like receptors, which discharge inflammatory mediators ${ }^{33}$ 
such as NO, which is a key mediator of platelet homeostasis. A decreased bioavailability of NO was found in patients with severe malaria infection, which may contribute to increased platelet activation and consumption. ${ }^{34}$

Malaria parasitemia and level of hematological parameters were evaluated in our study. This study reported that RBCs count, Hct, and Hgb concentration were found to be reduced in patients with high parasitemia compared with low and moderate parasitemia, likewise this study also reported that platelet count was significantly reduced among patients with high parasitemia compared with low and moderate parasitemia $(P<0.05)$ in congruent with a study conducted in Thailand. ${ }^{35}$ Total WBCs and neutrophil counts were higher in patients with high parasitemia compared to low and moderate parasitemia even though it is not statistically significant. In agreement, a previous study found a consistent positive relationship between WBC counts and parasite density in the malaria-infected patients. ${ }^{36}$ Another previous study also reported that there was no trend across quartiles of parasite density in relation to $\mathrm{WBC}$ counts during malaria infections. ${ }^{10}$ A study conducted in Thailand reported that WBC and neutrophil counts were significantly higher in patients with high parasitemia compared to those with low and moderate parasitemia. On the other hand, both lymphocyte and monocyte counts were significantly lower in patients with high parasitemia consistent to our finding. ${ }^{21}$

In our study, we have also evaluated lipid parameters of malaria-infected patients and healthy controls. It is believed that cholesterol is synthesized in the liver, which is the major site of Plasmodium infection. Although the parasites grow and multiply using nutrients from the host, they still cannot synthesize a majority of their own lipids and cholesterol in vivo.

In the present study, the serum levels of TC, HDL, LDL, and VLDL cholesterols in malaria-infected patients were lower than controls. This finding is in contrast to data reported in other studies that showed elevated levels of lipoproteins in patients suffering from malaria infection. ${ }^{37-40}$ On the contrary, a study reported that hyperlipidemia is one of the indicators of malaria infection; the hypothesis for the changes is basically due to increased VLDL production and increased mobilization of free fatty acids from adipose tissue in response to stress. ${ }^{41}$ However, the evidence of higher concentrations of serum lipids in the infected group might be due to adipose tissue lipolysis, impairment in lipoprotein lipase system, increases in de novo hepatic fatty acid synthesis, and suppression of fatty acid oxidation in severe infection. ${ }^{42}$

The decrease in serum TC and LDL cholesterol of malaria patients when compared with normal individuals has been reported by other studies ${ }^{43,44}$ that found no significant change in plasma cholesterol during and after malaria infection. Our findings of reduction in cholesterol levels in malarial infection added support to earlier reports where hypocholesterolemia was strongly associated with malaria. ${ }^{43,45,46}$ A systematic review and meta-analysis in agreement with our study reported that TC, HDL, and LDL concentrations were lower in malaria patients and compared to healthy controls. The decline was more pronounced and statistically significant during malaria compared to other febrile diseases but TG levels were found to be raised compared to healthy controls. ${ }^{47}$ This might be due to possible hypothesis of biological mechanisms involving host lipid alterations and the pathogenesis of malaria. The other hypothesis is that TG is derived from the phospholipids of RBC membrane following hemolysis and hypertriglyceridemia is described in disease with hemophagocytosis although not investigated. ${ }^{48}$

In contrast to our study, a study in Nigeria showed that TC and TG cholesterols of malaria-infected patients and controls showed no significant differences but were similar to our findings of serum LDL and HDL $(P<0.05)$ of malariainfected patients, which were below reference intervals. ${ }^{49,50}$ The decreased HDL might be due to reduction in the transport of cholesterol, esterification by lecithin cholesterol acyl transferase, and inhibition of liver enzyme by a parasite factor. The uptake of the host cholesterol and phospholipids by the parasite and adverse effects on HDL-generating enzyme are some of the factors leading to hypocholestrolemia. However, the rapid fall of HDL in malaria might be due to its extravasation, rather than a decreased rate of synthesis. ${ }^{13}$

Previous studies in culture of $P$. falciparum in vitro experiments proposed that uninfected RBCs in the culture serve as a major source for increased lipid content of malaria-infected cells, and an inverse relationship was observed between the levels of acidic phospholipids and cholesterol. ${ }^{51,52}$ Consistent with our study, the review noted that serum levels of VLDL and TG were significantly higher in malaria-infected patients. They further noted that oxidized LDL from malarial patients increased the endothelial expression of adhesion molecules that increased the risk of cardiovascular disease. ${ }^{47}$ Finally, although these changes in lipid and hematologic parameters in association with malaria infection are not novel, our findings have added more information, yet there is limited knowledge and few reports on alterations of blood parameters of malaria-infected individuals in Metema Hospital.

\section{Limitations of the study}

The main limitations of this study were confounding factors that may affect hematological parameters, such as micronutrient 
deficiencies and genetic backgrounds of patients, and crosssectional nature of the study design. To overcome other confounders such as common bacterial, viral, and helminth infections, we tried to screen patients based on clinical and laboratory methods for exclusion of infection besides malaria.

\section{Conclusion and recommendation}

This study revealed that lipid and hematological investigation are very important ways of estimating malaria parasite density. Thus, parameters of malaria-infected patients significantly differ from that of healthy controls. Investigations on lipid and hematological parameters are very important in estimating the density of malaria parasite, and performing hematography to assess the variety of morphological changes exhibited by RBCs associated with malaria infection is recommended for the future study in addition to hematological parameters counted with electronic cell counter.

\section{Acknowledgments}

The authors would like to acknowledge University of Gondar for funding and Metema Hospital laboratory staff for their cooperation in sample collection and processing.

\section{Author contributions}

All authors contributed toward data analysis, drafting and revising the paper and agree to be accountable for all aspects of the work.

\section{Disclosure}

The authors report no conflicts of interest in this work.

\section{References}

1. Hisaeda H, Yasutomo K, Himeno K. Malaria: immune evasion by parasites. Int J Biochem Cell Biol. 2005;37(4):700-706.

2. World Health Organization. World Malaria Report. Geneva: WHO reports; 2013.

3. Adugna A. Malaria in Ethiopia; 2011. Available from http://www. ethiodemographyandhealth.org/MedVectoredDiseasesMalaria.pdf. Accessed July 28, 2015.

4. Labaied M, Jayabalasingham B, Bano N, Cha SJ, Sandoval J, Guan G, Coppens I. Plasmodium salvages cholesterol internalized by LDL and synthesized de novo in the liver. Cell Microbiol. 2011;13(4):569-586.

5. Njoku OU, Ononogbu IC, Nwachukwu DE. Plasma cholesterol, B-carotene and ascorbic acid changes in human malaria. J Commun Dis. 1995;27(3):186-190.

6. Jiang J, Nilsson-Ehle P, Xu N. Influence of liver cancer on lipid and lipoprotein metabolism. Lipids Health Dis. 2006;5:4.

7. Fielding PE Fielding CJ. Dynamics of lipoprotein transport in the human circulatory system. New Compr Biochem. 2002;36:527-552.

8. Maina RN, Walsh D, Gaddy C, et al. Impact of Plasmodium falciparum infection on haematological parameters in children living in Western Kenya. Malar J. 2010;9(Suppl 3):S4.

9. Kimbi HK, Sumbele IU, Nweboh M, et al. Malaria and haematologic parameters of pupils at different altitudes along the slope of Mount Cameroon: a cross-sectional study. Malar J. 2013;12(1):193.
10. Erhart LM, Yingyuen K, Chuanak N, et al. Hematologic and clinical indices of malaria in a semi-immune population of western Thailand. Am J Trop Med Hyg. 2004;70(1):8-14.

11. Federal Democratic Republic of Ethiopia Population Census Commission. Summary and Statistical Report of the 2007 Population and Housing Census. Addis Ababa: Federal Democratic Republic of Ethiopia Population Census Commission; 2008.

12. Kassa B. Rice value chain in Metema District, North Gondar, Ethiopia: Challenges and Opportunities for Innovation. MA theis in Regional and Local Development Studies. 116p. Addis Ababa (Ethiopia): Addis Ababa University; 2010.

13. Krishna AP, Chandrika, kumar S, Acharya M, Patil SL. Variation in common lipid parameters in malaria infected patients. Indian J Physiol Pharmacol. 2009;53(3):271-274.

14. Halim S, Bretschneider TR, Li Y, Preiser PR, Kuss C, editors. Estimating Malaria Parasitaemia from Blood Smear Images. Control, Automation, Robotics and Vision, 2006 ICARCV'06 9th International Conference on; 2006: IEEE.

15. WH O. Guidelines for the treatment of malaria: World Health Organization. 2006.

16. Ali MSM, Al Karsani MS. Hematological changes malaria infected blood stored in blood bank refrigerator $\left(1-6^{\circ} \mathrm{C}\right) . J$ Sc Tech. 2009; 10(1):1-7.

17. Kotepui M, Phunphuech B, Phiwklam N, Chupeerach C, Duangmano S. Effect of malarial infection on haematological parameters in population near Thailand-Myanmar border. Malar J. 2014;13:218.

18. Francis U IZYA, Enosakhare A, Felix E. Haematological parameters of malaria infected patients in the University of Calabar teaching hospital, Calabar, Nigeria. J Hematol Thrombo Dis. 2014;2:171.

19. Sumbele IUN,Nkuo-Akenji T, Samje M, Ndzeize T, Ngwa EM, Titanji VPK. Hematological changes and recovery associated with untreated and treated Plasmodium faciparum infection in children in the mount Cameroon region. J Clin Med Res. 2010;2(9):143-151.

20. Bhawna S, Bharti A, Yogesh K, Reena A. Parasitemia and Hematological Alterations in Malaria: A Study from the Highly Affected Zones. Iran J Pathol. 2013;8(1):1-8.

21. Facer CA. Infection and Hematology. Oxford:Butterworth Heinmann Ltd; 1994. MG, Oldfield EC. Falciparum malaria. Infect Dis Clin North Am. 1996;10(4):747-775.

22. Agravat AH, Dhruva GA. Hematological changes in patients of malaria. J Cell Tissue Res. 2010;10(3):2325-2329.

23. Senthilkumaar P, Sarojini S. Haematological studies in malaria affected patients in North Chennai, Tamil Nadu. Euro J Exp Bio. 2013;3:199-205.

24. George IO E-EC. Haematological changes in children with malaria infection in Nigeria. J Med Medical Sci. 2011;2(4):768-771.

25. Osaro E, Jamilu MH, HM A, ACU E. Effect of plasmodium Parasitaemia on some haematological parameters in children living in Sokoto, North Western, Nigeria. Int J Clin Med Res. 2014;1(2):57-64.

26. Dangana A AJ, Nuhu A. Hematological changes associated with Salmonella typhi and Salmonella paratyphi in humans. Int J Biomed Health Sci. 2010;6(4):219-222.

27. Erkurt MA, Aydoğdu I, Bayraktar N, Kuku İ, Kaya E. The levels of nitric oxide in megaloblastic anemia. Turk J Hematol. 2009;26(4):197-200.

28. Pradhan P. Malarial anaemia and nitric oxide induced megaloblastic anaemia: a review on the causes of malarial anaemia. J Vector Borne Dis. 2009;46(2):100-108.

29. Kochar DK, Kochar SK, Agrawal RP, et al. The changing spectrum of severe falciparum malaria: a clinical study from Bikaner (northwest India). J Vector Borne Dis. 2006;43(3):104-108.

30. Johnston V, Stockley JM, Dockrell D, et al. Fever in returned travelers presenting in the United Kingdom: recommendations for investigation and initial management. $J$ Infect. 2009;59(1):1-18.

31. Weatherall DJ, Miller LH, Baruch DI, Marsh K, Doumbo OK, CasalsPascual C, Roberts DJ. Malaria and the red cell. Hematology Am Soc Hematol Educ Program. 2002:35-57.

32. Hutton R, Lafan, M, Tuddenham E. Normal haemostasis. In: Hoffbrand A, Lewis S, Tuddenham E. editors. Postgraduate Hematology, 4th ed. McGraw-Hill; UK, Butterworth-Heinmann Ltd. 2002:1339-1356. 
33. Morrell CN, Aggrey AA, Chapman LM, Modjeski KL. Emerging roles for platelets as immune and inflammatory cells. Blood. 2014;123(18): 2759-2767.

34. Yeo TW, Lampah DA, Gitawati R, et al. Impaired nitric oxide bioavailability and L-arginine reversible endothelial dysfunction in adults with falciparum malaria. J Exp Med. 2007;204(11):2693-2704.

35. Kotepui M, Piwkham D, PhunPhuech B, Phiwklam N, Chupeerach C, Duangmano S. Effects of malaria parasite density on blood cell parameters. PLoS One. 2015;10(3):e0121057.

36. McKenzie FE, Prudhomme WA, Magill AJ, et al. White blood cell counts and malaria. J Infect Dis. 2005;192(2):323-330.

37. Nilsson-Ehle I, Nilsson-Ehle P. Changes in plasma lipoproteins in acute malaria. J Inter Med. 1990;227(3):151-155.

38. Davis TM, Sturm M, Zhang YR, Spencer JL, Graham RM, Li GQ, Taylor RR. Platelet-activating factor and lipid metabolism in acute malaria. $J$ Infect. 1993;26(3):279-285.

39. Vial HJ, Eldin P, Tielens AG, Vanhellmond JJ. Phospholipids in parasite protozoa. Mol Biochem Parasitol. 2003;126(2):143-154.

40. Ndukaku OY, Emmauel EU, Loveth UE, Oluchi OI. Evaluation of some serum kidney functions and lipid profile of malaria patients in south eastern Nigeria. Rom J Biochem. 2015;52(1):39-49.

41. Akanbi OM. Effect of malaria infection on oxidative stress and lipid profile in pregnant women. J Med Med Sci. 2013;4(3):128-133.

42. Bansal D, Bhatti HS, Sehgal R. Role of cholesterol in parasitic infections. Lipids Health Dis. 2005;4:10.

43. Grellier P, Rigomier D, Clavey V, Fruchart JC, Schrevel J. Lipid traffic between high density lipoproteins and Plasmodium falciparum-infected red blood cells. J Cell Biol. 1991;112(2):267-277.
44. Miller LH, Baruch DI, Marsh K, Doumbo OK. The pathogenic basis of malaria. Nature. 2002;415(6872):673-679.

45. Badiaga S, Barrau K, Parola P, Brouqui P, Delmont J. Contribution of non-specific laboratory test to the diagnosis of malaria in febrile travellers returning from endemic areas: Value of hypocholesterolaemia. J Travel Med. 2002;9(3):117-121.

46. Al-Omar IA, Eligail AM, Al-Ashban RM, Shah AH. Effect of falciparum malaria infection on blood cholesterol and platelets. J Saudi Chem Soc. 2010;14(1):83-89.

47. Visser BJ, Wieten RW, Nagel IM, Grobusch MP. Serum lipids and lipoproteins in malaria -a systematic review and meta-analysis. Malar J. 2013;12:442.

48. Bouyou-Akotet MK, Mawili Mboumba DP, Guiyedi V, Pemba Mihindou M, Maryvonne Kombila M. Altered total cholesterol and triglyceride level during the course of Plasmodium falciparum in children. $J$ Parasitol Vector Biol. 2014;6(11):174-180.

49. Chikezie PC, Okpara RT. Serum lipid profile and hepatic dysfunction in moderate plasmodium falciparum infection. Sci J Microbiol. 2013; 2(8): $158-165$.

50. Sibmooh N, Yamanont P, Krudsood S, Leowattana W, Brittenham G, Looareesuwan S, Udomsangpetch R. Increased fluidity and oxidation of malarial lipoproteins: relation with severity and induction of endothelial expression of adhesion molecules. Lipids Health Dis. 2004;3:15.

51. Gutman J, Green M, Durand S, et al. Mefloquine pharmacokinetics and mefloquine-artesunate effectiveness in Peruvian patients with uncomplicated Plasmodium falciparum malaria. Malar J. 2009;8(1):58-62.

52. Laxminarayan R, Gelband H. A global subsidy: key to affordable drugs for malaria?Health Aff (Millwood). 2009;28(4):949-961.
Pathology and Laboratory Medicine International

\section{Publish your work in this journal}

Pathology and Laboratory Medicine International is a peer-reviewed, open access journal focusing on innovative basic research and translational research related to pathology or human disease. The journal includes original research, updates, case reports, reviews and commentaries on current controversies. The manuscript management system is completely

\section{Dovepress}

online and includes a very quick and fair peer-review system. Visit http://www.dovepress.com/testimonials.php to read real quotes from published authors. 